\title{
Forthcoming meetings
}

\author{
1987
}

8-10. 10. 32nd Annual Meeting of the Deutsche EEG-Gesellschaft (German Section of the International Federation of Societies for Electroencephalography and Clinical Neurophysiology), Ludwigshafen, FRG. - Information: Prof. Dr. med. K. Lowitzsch, Neurologische Klinik, Klinikum Ludwigshafen, Bremserstrasse 79, D-6700 Ludwigshafen, FRG

18.10. XIII International Symposium of the Fulton Society on "MEMORY", San Francisco USA. Together with the 112th American Neurological Association Annual Meeting (19.21.10.). - Information: Prof. Dr. V.Soriano, Calle Buenos Aires 363, Montevideo, Uruguay

10-12.3. Medical Imaging and Expert Systems Applied to Medicine, Lyons, France. Organised by <Les Entretiens des Lyons > in association with VISIOMED 88 and with the co-operation of the Society of Electricians and Electronics Specialists, the College of Radiology Teachers in France and the French Society of Biophysics and Nuclear Medicine. The conference deals with the relationship between medical world, computer science and artificial intelligence. - Information: Les Entretiens de Lyons, 55 montée de Choulàns, F-69323 Lyons cedex 05, France

17-19.3. International Meeting on Artificial Intelligence and Medical Imaging (Radiology) and Introduction to Expert Systems in Radiology, Strasbourg, France. - Information: R.M. Kipper, C.H.R., Hôpital Central, B.P. 426, F-67091 Strasbourg cedex, France

5-9.6. 9th International Symposium on Parkinson's Disease, Jerusalem, Israel. - Information: A.D. Korczyn, P.O.B. 50006, Tel Aviv 61500, Isreal

19-22.6. First Annual Meeting of the European Neurological Society, Nice, France. The European Neurological Society (ENS) has been founded to foster cooperation between neurologists and those working in related disciplines within Europe. Meetings will be held biennially. The participation of individuals from other areas of the world is welcomed. The biennial meetings will provide instructional courses for neurologists in training, up-date symposia, and sessions for the presentation of original work, either as platform or poster presentations. The teaching programme will include courses on peripheral neuropathy, neuroimaging, dementia, and neurovirology/neuroimmunology. There will be symposia on physiological aspects of cerebral blood flow, neuromediators, and neurogenetics. Active membership of the ENS will be by election from clinicians and scientists whose chief interest is directed towards practice, teaching or research in Neurology and cognate fields. Active membership will become effective only after contribution to a meeting of the ENS. Junior members may be elected from members engaged in postgraduate studies in neurology or related disciplines. - Information: Prof. G.Said, Service de Neurologie, Hôpital de Bicêtre, F-94275 Le Kremlin Bicêtre Cédex, France 